\title{
Infections Following Kidney Transplant in Children: A Single-Center Study
}

\author{
Alexandre Fernandes ${ }^{1 *}$, Liliana Rocha ${ }^{2}$, Teresa Costa², Paula Matos ${ }^{2}$, Maria Sameiro Faria ${ }^{2}$, \\ Laura Marques ${ }^{1}$, Conceição Mota ${ }^{2}$, António Castro Henriques ${ }^{3}$ \\ ${ }^{1}$ Pediatric Infectious Diseases and Immunodeficiency Department, Centro Hospitalar do Porto, Oporto, \\ Portugal \\ ${ }^{2}$ Pediatric Nephrology Department, Centro Hospitalar do Porto, Oporto, Portugal \\ ${ }^{3}$ Kidney Transplant Department, Centro Hospitalar do Porto, Oporto, Portugal \\ Email: ${ }^{*}$ xanofernandes@gmail.com
}

Received 18 July 2014; revised 17 August 2014; accepted 15 September 2014

Copyright (C) 2014 by authors and Scientific Research Publishing Inc.

This work is licensed under the Creative Commons Attribution International License (CC BY).

http://creativecommons.org/licenses/by/4.0/

(c) (i) Open Access

\section{Abstract}

Introduction: Infections are a major cause of morbidity and mortality in pediatric patients undergoing kidney transplantation (KT). Aim and Methods: To determine the patterns of infectious complications during the first 6 months post transplantation, we report our single center experience with data from pediatric kidney recipients transplanted between 2006 and 2011 . Results: Thirty-two children (20 males) were submitted to KT. The most common cause of end-stage renal disease (ESRD) was congenital anomalies of the kidney and urinary tract (CAKUT) accounting for $62 \%$. Over the first 6 months post-transplant period, twenty-eight (87.5\%) children developed a total of 77 infections, mainly urinary tract infections (UTI) (64.9\%). CAKUT etiology of ESRD and UTI before KT increased the risk to develop more than one episode of UTI [71.4\% vs. $14.3 \%$ and $81.8 \%$ vs. $18.2 \%$, respectively; $p<0.05]$. Twenty-three $(29.9 \%)$ viral infections occurred. Cytomegalovirus (CMV) was the most common opportunistic pathogen, occurred in 11 patients and was more frequently in those with a donor (D)+/recipient (R)- CMV sero-status [74.5\% vs. 25.5\% $(p<0.05)]$. A polyomaviruses (BKV) disease with nephropathy and meningitis was registered. The majority of infectious episodes had mild or moderate severity. No deaths occurred. Conclusion: A significant number of patients presented infectious complications during the first 6 months post transplantation. UTI are the most common type of infection, followed by viral infections, particularly CMV. Recognition, prevention and early treatment of infections are of major importance.

\section{Keywords}

CMV Infection, Immunosuppression, Kidney Transplantation, Urinary Tract Infections

"Corresponding author. 


\section{Introduction}

Kidney transplantation (KT) is the treatment of choice for end-stage renal disease (ESRD) in children [1] [2]. Despite improvements on immunosuppressive therapy and surgical techniques, infections remain important complications and have been associated with increased morbidity and graft rejection [3] [4]. Indeed, infection is the predominant reason for hospitalization post transplantation and in the last few decades the successive emergence of new viral infections has been observed [5]. Specifically, cytomegalovirus (CMV) infections have been prominent in kidney transplant recipients since the 1980s, followed by Ebstein-Barr virus (EBV)-induced post transplantation lymphoproliferative disorder (PTLD) since the 1990s, and BK-virus-associated allograft nephropathy (BKVAN) in the last 10 years [5]. Infections are not only a significant source of morbidity and hospitalization but an important source of patient mortality and graft loss.

The immunosuppressive regimens currently in use are accompanied by a well-defined temporal sequence of infections [6]. During the first post-transplant month, the most frequent categories of infection are related to technical problems (including surgical site infections), urinary tract infections, vascular access infections, and pulmonary infections [7]. During this period, more than $90 \%$ of all infections are caused by bacteria and fungi and opportunistic infections are unusual [7] [8]. The greatest risk of life-threatening infection occurs between 1 and 6 months post transplantation, when the effects of immunosuppressive therapy peak [8] [9]. During this period, most common infections are opportunistic agents: virus like cytomegalovirus (CMV), polyomaviruses (BKV), Epstein-Barr Virus (EBV) and fungi (aspergillus). These opportunistic infections can occur with minimal epidemiological exposure and are related to the immunosuppression [7] [10]. CMV is the most common opportunistic organism encountered during this period [6] [9], and causes significant morbidity by direct infection and its immunomodulatory effects predispose to other infectious complications [5].

Although rejection rates have significantly decreased with the introduction of more potent immunosuppressive regimens, infections became a major problem in the transplant recipients [3] [10]. Death-censored graft loss from infectious complications is on the rise [7]. Similar to rejection rates, infection rates should be analyzed periodically in order to improve post transplantation outcome.

The purpose of this study was to analyze the patterns of infectious complications during the first 6 months post transplantation in our department.

\section{Material and Methods}

\subsection{Design and Study Protocol}

A retrospective study was performed to review the infectious complications over the first six months post transplantation, in children undergoing KT between January 2006 and December 2011. Two patients were excluded from the analysis because they experienced early graft loss, not related to infection.

Data were collected by clinical files review and included: all infectious episodes, clinical signs associated to these episodes, severity, renal function when infections occurred, pharmacological treatment, kidney and patient survival. We also divided the post transplant follow-up into two periods: less than 1 month and from 1 to 6 months.

\subsection{Anti-Infectious Prophylaxis}

In all patients prophylaxis consisted of intravenous $50 \mathrm{mg} / \mathrm{kg}$ cefoxitin (single dose, maximum $1000 \mathrm{mg}$ ) before the transplantation surgery and trimethoprim-sulfamethoxazole orally for Pneumocystis jirovecci prophylaxis for the first 6 months. Oral nystatin was added in the first month as antifungal prophylaxis. For CMV prophylaxis, oral valgancyclovir $(3.5 \times$ body surface area $\times$ creatinine clearance) was given for the first 6 months in all recipients, except $\mathrm{D}(-) / \mathrm{R}(-)$ sero-CMV status. Intravenous $\mathrm{CMV}$ immunoglobulin $(1 \mathrm{~mL} / \mathrm{Kg}$, weekly) was administered to $\mathrm{D}+/ \mathrm{R}-\mathrm{CMV}$ within the first month after transplantation.

\subsection{Immunosuppressive Therapy}

The protocol in use in our institution included induction with antibodies anti-T cell (antithymocyte globulin or daclizumab), calcineurin inhibitors, mycophenolate mofetil and prednisolone, associated to maintenance immunosuppressive therapy with low doses of mofetil mycofenolate $\left(300 \mathrm{mg} / \mathrm{m}^{2}\right.$; bid); tacrolimus (target-levels range of $8-10 \mathrm{ng} / \mathrm{ml}$ in the first month) and very low corticosteroids doses. 


\subsection{Definitions}

UTI was diagnosed in the presence of a positive urine culture (more than $10^{5}$ colony-forming units). A second UTI was diagnosed if between first and second episode there was a time free of symptoms and with a negative urine culture.

CMV infection was considered to be present if one or more of the following findings was noted: detection of one or more cells positive for CMV pp65 antigen per $10^{5}$ leukocytes; seroconversion with the appearance of anti-CMV IgM antibodies; a fourfold increase in preexisting anti-CMV IgG titers; detection of CMV-DNAemia by molecular techniques; and/or isolation of the virus by culture of the throat, buffy coat, or urine. CMV disease requires clinical signs and symptoms, such as fever, leucopenia, or organ involvement.

Acute rejection was defined as an acute rejection episode treated either based upon clinical presumption or biopsy confirmed.

Graft dysfunction was defined as an episode when serum creatinine rise more than $0.5 \mathrm{mg} / \mathrm{dl}$ of previous values.

Infection with mild or moderate severity was defined when there was no need for hospitalization or when there was hospitalization only for anti-infectious intravenous therapy (without other organ dysfunction).

\subsection{Surveillance}

During the post transplant period, the patients were closely monitored for infections. Urine culture was performed in all outpatient visits and whenever symptoms suggestive of UTI or unexplained fever. CMV antigenemia (pp65 assays) was performed in the first month and every two months or when clinical suspicion of infection. BK virus in urine (by nucleic acid detection) was also monitored monthly: if BKV positive in urine a quantitative PCR BKV in plasma was also performed. Any fever (temperature higher than $38^{\circ} \mathrm{C}$ ) was investigated systematically with white blood count and C-reactive protein serum level.

\subsection{Treatment of Infections}

Empirical UTI treatment was performed with antimicrobials covering the common gram-negative organisms or based on the susceptibility of the last pathogen identified. Upon identification of the etiologic agent, specific antimicrobial therapy was prescribed according to the microorganism susceptibility.

Therapeutic doses of valgancyclovir were given in the presence of a CMV infection and Intravenous gancyclovir was administered in CMV disease.

Preemptive reduction in immunosuppression was always done in BKV infection.

\subsection{Statistical Analyses}

Results were reported as mean, median and range for the quantitative variables and percentages for the categorical variables. Patients that presented infections were compared with those that do not had infections using the Fisher's exact test for categorical variables and differences between means were analyzed by Student $t$ test or Mann-Whitney U test. P-values of 0.05 or less were considered statistically significant. All the statistical analyses were performed using SPSS version 20.0 (SPSS Inc., Chicago, IL, USA).

\section{Results}

Thirty-two patients underwent KT between January 2006 and December 2011, 20 (62.5\%) male, with a mean patient age at KT of 11.5 years (range from 2 to 17 years). Twenty seven (84.4\%) received KT from deceased donors and the remaining 5 (15.6\%) from living related donors. CAKUT were the most common cause of renal disease accounting for $62 \%$. The distribution of primary renal diseases is shown in Table 1 . Fifteen (46.9\%) children had UTI before undergoing KT. The donor (D)/recipient (R) sero-CMV status was: $\mathrm{D}(+) / \mathrm{R}(-)$ : 10 (31.3\%); $\mathrm{D}(-) / \mathrm{R}(+): 8(25 \%) ; \mathrm{D}(+) / \mathrm{R}(+): 9$ (28.1\%); $\mathrm{D}(-) / \mathrm{R}(-): 5(15.6 \%)$. The immunossupressive therapy included induction with antibodies (84.4\% with antithymocyte globulin and $15.6 \%$ with basiliximab) associated with a triple regimen with tacrolimus, mycophenolate mofetil and low doses of prednisolone. The mean posttransplant hospitalization time was 12.9 days (range: 7 to 37 days).

Twenty-eight (87.5\%) children developed a total of 77 infection episodes (2.7 infections /patient) over the first 6 months post-transplant. The types of infections in our population are shown in Table 2. Seventy-eight 
percent of these infectious episodes occurred between 1 and 6 months and 22\% in the first month post transplantation. There was a predominance of UTI (64.9\%), followed by viral infections (29.8\%). Four children had bacterial infections related to surgical procedure ( 1 surgical site infections, 1 peritonitis and 2 infected lymphocele). There had been no invasive fungal or mycobacterial infections. The infection episodes distribution in the first month and between 1 - 6 months post-transplant is shown in Figure 1.

UTI was the main infection occurring during this period (50 episodes in 21 (66\%) patients) with an incidence of 2.4 episodes/child with UTI. Eleven (34.4\%) patients had more than one UTI episode. More than one episode of UTI was more frequent in patients with CAKUT etiology of ESRD and UTI before KT [ $71.4 \%$ vs. 14.3\% and $81.8 \%$ vs. $18.2 \%$, respectively ( $<0.05)$.

Fourteen (28\%) episodes of UTI were febrile. Children with UTI before KT had higher risk to develop febrile UTI $[100 \%$ vs. $0 \%(\mathrm{p}<0.05)]$. UTI were mainly caused by Gram-negative bacteria (86\%); Klebsiella pneumonia (40\%) and Escherichia coli (32\%) were the most common agents (Table 3). A multi-drug resistant microorganism was isolated in 12 (24\%) UTI episodes in 7 patients; these microorganisms were more frequent in patients with CAKUT etiology of ESRD $[100 \%$ vs. $0 \%(\mathrm{p}<0.05)]$ and were more frequently identified in febrile UTI [80\% vs. $18.8 \%(\mathrm{p}<0.05)]$.

Table 1. Demographic characteristics and etiology of ESRD of 32 children submitted to kidney transplantation; ESRD: End-stage renal disease; CAKUT: Congenital anomalies of the kidney and urinary tract.

\begin{tabular}{|c|c|}
\hline \multicolumn{2}{|l|}{ Demographic characteristics } \\
\hline Male & 20 (62.5\%) \\
\hline Age at transplantation & $\begin{array}{l}\text { Mean: } 11.5 \text { years } \\
\text { (Minimum: } 2 \text { years; Maximum: } 17 \text { years) }\end{array}$ \\
\hline Caucasian & $32(100 \%)$ \\
\hline Infections pre-KT & $21(65.6 \%)$ \\
\hline UTI & 15 (46.9\%) \\
\hline Peritonitis & $6(18.8 \%)$ \\
\hline \multicolumn{2}{|l|}{ Causes of ESRD } \\
\hline CAKUT & $20(62.5 \%)$ \\
\hline Posterior urethral valves & 6 \\
\hline Neurogenic bladder & 5 \\
\hline Renal dysplasia & 4 \\
\hline Reflux nephropathy & 2 \\
\hline Other & 3 \\
\hline Glomerular & $4(12.5 \%)$ \\
\hline Cystic disease & $3(9.4 \%)$ \\
\hline Other & $3(9.4 \%)$ \\
\hline Unknown & $2(6.2 \%)$ \\
\hline
\end{tabular}

Table 2. Infections occurred during the first 6 months after kidney transplantation [UTI-urinay tract infection; CMV-Cytomegalovirus; Bk-Polyomavirus; ${ }^{*}$ Rhinovirus, Influenza].

\begin{tabular}{ll}
\hline Pos Transplant infection & \\
\hline Number of infections & 77 -occurred in 28 children \\
Number of infections per child & 2.4 \\
Type of Infections & $54(70.1 \%)$ \\
Bacterial infections & 50 -occurred in 21 children \\
UTI & 4 \\
Other bacterial infections & \\
Viral infections & $23(29.9 \%)$-occurred in 19 children \\
CMV & 11 \\
Bk virus & 3 \\
Herpes simplex 1 & 4 \\
Herpes zoster & 1 \\
Epstein Barr & 1 \\
Miscelaneous & 3 \\
Invasive fungal infections & \\
\hline
\end{tabular}


Table 3. Urinary tract infections occurred in the first 6 months after kidney transplantation [UTI-urinay tract infection; KT-Kidney transplantation].

\begin{tabular}{ll}
\hline & Number (\%) \\
\hline Episodes of UTI & 50 \\
Patients with UTI during first month after KT & $14(43.8 \%)$ \\
Episodes of febrile UTI & $14(28 \%)$ \\
Gram-negative bacteria & \\
Escherichia coli & $16(32 \%)$ \\
Klebsiella & $20(40 \%)$ \\
Proteus & $1(2 \%)$ \\
Citrobacter freundii & $4(8 \%)$ \\
Enterococcus & $2(4 \%)$ \\
Gram-positive bacteria & $7(14 \%)$ \\
\hline
\end{tabular}

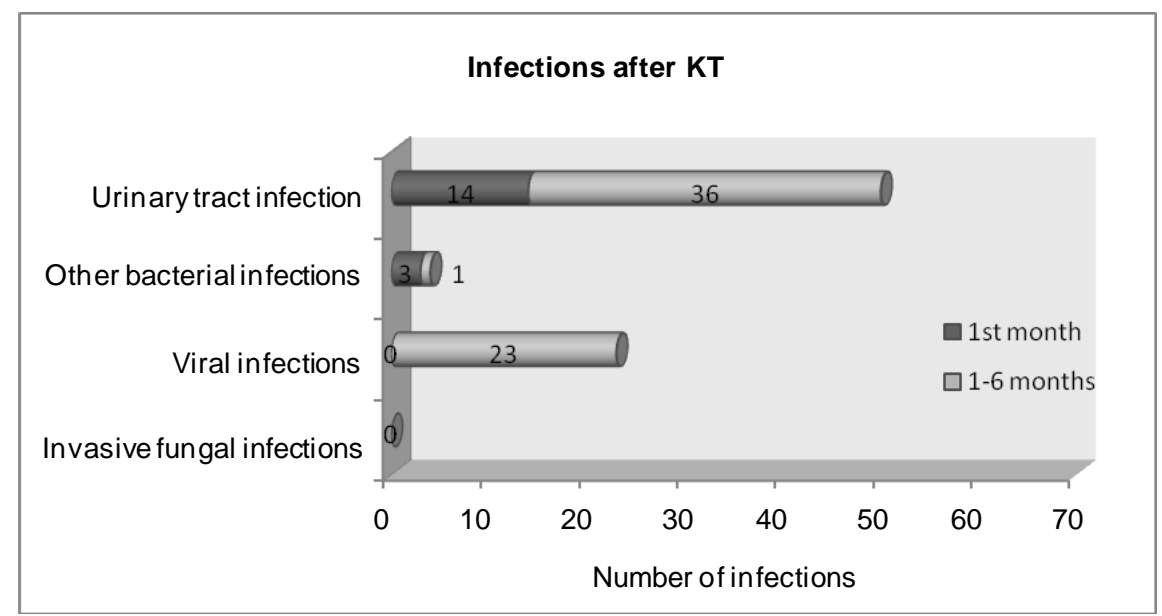

Figure 1. Infections occurred after kidney transplantation divided in 2 periods: $1^{\text {st }}$ month and between 1 - 6 months.

CMV infection was recorded in 11 patients (34.4\%), one of these with symptomatic infection (e.g., CMV disease). This infection occurred more frequently in patients with a $\mathrm{D}(+) / \mathrm{R}(-)$ CMV sero-status $[74.5 \%$ vs. 25.5\% $(\mathrm{p}<0.05)]$. Three children had BKV infection one of them with special severity with nephropathy and meningitis.

During the observation period one patient had an acute rejection episode successfully treated with 3-day course of intravenous methylprednisolone (10 mg/Kg/day).

Two patients presented serious infections: one urosepsis with shock requiring admission to intensive care unit and one BKV disease with meningitis. All the other infections were of mild or moderate severity.

Eighteen (23.4\%) infection episodes were associated with acute reversible graft dysfunction. None of the patients died during this period.

\section{Discussion}

Renal transplantation is the treatment of choice for children with ESRD and frequently restores the potential for normal growth and development with improved morbidity and mortality rates compared to dialysis. Short-term renal graft survival rates have improved with the use of newer immunosuppressive medications but carry the risk of increased infectious complications [11].

In this group, twenty-eight (87.5\%) children developed a total of 77 infection episodes over the first 6 months post-transplant. The majority of these infectious episodes occurred between 1 and 6 months (78\%) and the remaining in the first month post transplantation. As previously described, UTI and others bacterial infections (related to surgery) predominate in the first month and opportunistic infections were unusual; between 1 and 6 
months post transplantation a high frequency of UTI persisted and viral infections occurred, in particular CMV and BKV infections, matching the typical infection patterns described [6] [7] [9].

According to the literature UTI is the most common form of bacterial infection in renal transplant and the data presented demonstrate that prevalence. Multiple episodes of UTI were more frequent in urologic causes of ESRD [5] [6] [8] [12]. Urinary tract abnormalities, bladder pathology with abnormal urodynamic assessment and a significant post-micturition residue requiring urinary catheterization is frequent. In our population CAKUT were the main cause of ESRD, accounting for $62.5 \%$, and we observed in these patients a greater risk to develop more than 1 UTI episode. The presence of UTI episodes before KT is also associated with a greater risk to develop multiple UTI episodes post transplantation.

In our study, the prevalence of febrile UTI was $28 \%$ which was in agreement with previous reports in pediatric renal transplantation studies that range between 15\% and 33\% [1] [2]. Febrile UTI after KT may lead to kidney damage, negatively affecting long-term graft survival by scarring and interstitial injury, although precise data for the pediatric population are scarce. Therefore, in order to prevent allograft damage induced by febrile UTI, aggressive and specific treatment is mandatory [2]. In our patients antibiotic therapy was frequently initiated if bacteriuria was present and severe infections were infrequently found.

The most frequent organisms causing UTI in our population were Klebsiella species followed by Escherichia coli. Escherichia coli was isolated less frequently than in the general pediatric population, where it is found up to $80 \%$ [13]. This epidemiologic change may be due to underlying immunosuppression, colonization and mainly to the higher prevalence of bladder malformations in this population [8]. Unusual organisms such as Pseudomonas species were isolated in $8 \%$ of the children in this study and multiple antibiotic resistances were also seen in patients with abnormal lower urinary tract and neurogenic bladder.

The incidence of other bacterial infections related to surgery was low in the present study, as in other recent studies [14] [15]. The lower incidences of those infections in recent years may be partly due to improvements in surgical transplant techniques and prophylaxis strategies.

Viral infections are an important concern between the 1 - 6 months post-transplantation in recipients' kidney transplants. CMV infection is one of the most common infections after transplantation, only preceded by UTI as reported in other studies [9]. The major determinants of CMV infection are an active or latent CMV agent in the donor or recipient and the dose, duration and type of immunosuppressive therapies [16]. The induction with lymphocyte depletion is also associated with an increase of CMV infections [16] [17]. In our cohort about a third of patients had CMV infection although only one presented CMV disease. CMV infections were more frequent in $\mathrm{D}(+) / \mathrm{R}(-)$ positive donors as previously reported [5] [12]. The widespread use of prophylactic and/or preemptive antiviral therapy has greatly reduced the incidence of CMV disease and can explain the low rate of CMV disease in our population. Without preventive therapy, the incidence of symptomatic CMV infection in such recipients would be about $50 \%$ to $65 \%$ [5]. Literature documents a relation between CMV infection and acute rejection [5] [12]; in our cohort, only one KT recipient had an acute rejection episode, during the observation period.

In kidney transplant recipients, BKV can be responsible to allograft nephropathy [5] and its incidence in pediatric KT ranges from $3 \%$ to $8 \%$; risk factors include aggressive immunosuppression and recent treatment for acute rejection [5]. We identified 3 children with BK infection, one case with nephropathy and BK meningitis. The cornerstone of the treatment of BKV infection is to decrease the immunosuppressive therapy. In our patient with a disseminated disease we also administered cyprofloxacin, cidofovir and intravenous immunoglobulin with a successful outcome [18].

The use of induction immunosuppression with polyclonal antibodies (84.4\%) in our population probably increased the risk of infection [17]. On the other hand, a very low number of acute rejection episodes were observed and no additive anti-rejection therapy was needed. Although a potent induction antibody was often used in our institution for pediatric recipients from deceased donors, the cumulative immunosuppression is not considered too burden.

The risk of non Hodgkin lymphoma (PTLD) was associated to Epstein Barr virus infection, and in children was commonly attributed to primary EBV infections from an EBV-positive renal graft [19]. In our series no PTLD was registered during the observation period. However a longer follow-up period is needed.

Study limitations: the data collected from files may not have all information. Indeed, some mild infections (like could infection) could be treated at home with no records in clinical files. Our study only considered infections occurred during first 6 months after KT and not assessed infections occurred after this period. 


\section{Conclusion}

The current opinion is that the optimal approach to preserving renal allograft function is to minimize the immunosuppressive burden, thereby achieving a balance between the risk of rejection and infections complications. The antimicrobial prophylaxis protocol, close monitoring and an early treatment of infections could justify the mild or moderate severity of the almost all infections over the observation period in our pediatric kidney recipients. The long term care of transplant recipients should include all preventive measures; close monitoring for any subtle infections and immunosuppression must be prudently managed and adjusted to the patients to reach a favorable outcome.

\section{References}

[1] Esezobor, C.I., Nourse, P. and Gajjar, P. (2012) Urinary Tract Infection Following Kidney Transplantation: Frequency, Risk Factors and Graft Function. Pediatric Nephrology, 27,651-657 http://dx.doi.org/10.1007/s00467-011-2044-1

[2] Ulrike, J.M. and Kemper, J. (2009) Urinary Tract Infections in Children after Renal Transplantation. Pediatric Nephrology, 24,1129-1136 http://dx.doi.org/10.1007/s00467-007-0690-0

[3] Green, M. and Michaels, M.G. (2012) Infections in Pediatric Solid Organ Transplant Recipients. Journal of the Pediatric Infectious Diseases Society, 1,144-151 http://dx.doi.org/10.1093/jpids/pir001

[4] Allen, U. and Green, M. (2010) Prevention and Treatment of Infectious Complications after Solid Organ Transplantation in Children. Pediatric Clinics of North America, 57, 459-479. http://dx.doi.org/10.1016/j.pcl.2010.01.005

[5] Neu, A. and Dharnidharka, V. (2008) Prevention and Treatment of Infectious Complications in Pediatric Renal Allograft Recipients. In: Geary, D.F. and Schaefer, F., Eds., Comprehensive Pediatric Nephrology, Mosby-Elsevier, Philadelphia, 967-973

[6] Rubin, R. (1993) Infectious Disease Complications of Renal Transplantation. Kidney International, 44, 221-236. http://dx.doi.org/10.1038/ki.1993.234

[7] Parasuramana, R., Samarapungavana, D. and Venkatb, K.K. (2010) Updated Principles and Clinical Caveats in the Management of Infection in Renal Transplant Recipients. Transplantation Reviews, 24, 43-51. http://dx.doi.org/10.1016/j.trre.2009.09.001

[8] Mencarelli, F. and Marks, S. (2012) Non-Viral Infections in Children after Renal Transplantation. Pediatric Nephrology, 27, 1465-1476. http://dx.doi.org/10.1007/s00467-011-2099-z

[9] Charfeddine, K., Zaghden, S., Kharrat, M., Kamoun, K., Jarraya, F. and Hachicha, J. (2005) Infectious Complications in Kidney Transplant Recipients, A Single-Center Experience. Transplantation Proceedings, 37, 2823-2825. http://dx.doi.org/10.1016/j.transproceed.2005.05.009

[10] Fishman, J. (2007) Infection in Solid-Organ Transplant Recipients. The New England Journal of Medicine, 357, 26012614. http://dx.doi.org/10.1056/NEJMra064928

[11] Dharnidharka, V.R.1., Caillard, S., Agodoa, L.Y. and Abbott, K.C. (2006) Infection Frequency and Profile in Different Age Groups of Kidney Transplant Recipients. Transplantation, 81, 1662-1667. http://dx.doi.org/10.1097/01.tp.0000226068.66819.37

[12] Ranchin, B., Hees, L., Stamm, D., Bertholet-Thomas, A., Billaud, G., Lina, G., Cochat, P. and Gillet, Y. (2011) Transplantation rénale et infection chez l'enfant. Néphrologie \& Thérapeutique, 7, 608-610 http://dx.doi.org/10.1016/j.nephro.2011.11.006

[13] Jodal, U. and Winberg, J. (1987) Management of Children with Unobstructed Urinary Tract Infection. Pediatric Nephrology, 1, 647-656. http://dx.doi.org/10.1007/BF00853603

[14] Gargah, T., Labessi, A., Ounissi, M., Derouiche, A., Chokri, Z., Abdallah, T., Chebil, M. and Lakhoua, M.R. (2011) Early Infections in Children Following Renal Transplantation. La Tunisie Médicale, 89, 26-30.

[15] Maraha, B., Bonten, H., van Hooff, H., Fiolet, H., Buiting, A.G. and Stobberingh, E. (2001) Infectious Complications and Antibiotic Use in Renal Transplant Recipients during a 1-Year Follow-Up. Clinical Microbiology and Infection, 7, 619-625. http://dx.doi.org/10.1046/j.1198-743x.2001.00329.x

[16] Conceição, M., Lassalete, M., Costa, T., Leonidio, D., Almeida, M., Santos, J., Sameiro Faria, M., Castro Henriques, A. and Almeida, R. (2010) Nineteen Years of Experience Utilizing Anti-T-Lymphocyte Globulin Induction in Pediatric kidney Transplantation. Annals of Transplantation, 15, 84-91.

[17] Issa, N. and Fishman, J. (2009) Infectious Complications of Antilymphocyte Therapies in Solid Organ Transplantation. Clinical Infectious Diseases, 48, 772-786. http://dx.doi.org/10.1086/597089

[18] Rocha, A., Faria, S., Costa, T., Marques, L., Freitas, C. and Mota, C. (2013) BK Virus Nephropathy Complicated with Meningoencephalitis after Kidney Transplantation. Pediatric Transplantation, 18, E48-E51. 
http://dx.doi.org/10.1111/petr.12209

[19] Opelz, G., Daniel, V., Naujokat, C. and Döhler, B. (2009) Epidemiology of Pretransplant EBV and CMV Serostatus in Relation to Posttransplant Non-Hodgkin Lymphoma. Transplantation, 88, 962-967. http://dx.doi.org/10.1097/TP.0b013e3181b9692d

\section{Abbreviations}

BKV: Polyomaviruses; CAKUT: Congenital Anomalies of the Kidney and Urinary Tract; CMV: Cytomegalovirus; D/R: Donor/Recipient; EBV: Epstein-Barr Virus; ESRD: End-Stage Renal Disease; Ig: Immunoglobulin; KT: Kidney Transplantation; PTLD: Post-Transplant Lymphoproliferative Disorder; UTI: Urinary Tract Infections 
Scientific Research Publishing (SCIRP) is one of the largest Open Access journal publishers. It is currently publishing more than 200 open access, online, peer-reviewed journals covering a wide range of academic disciplines. SCIRP serves the worldwide academic communities and contributes to the progress and application of science with its publication.

Other selected journals from SCIRP are listed as below. Submit your manuscript to us via either submit@scirp.org or Online Submission Portal.
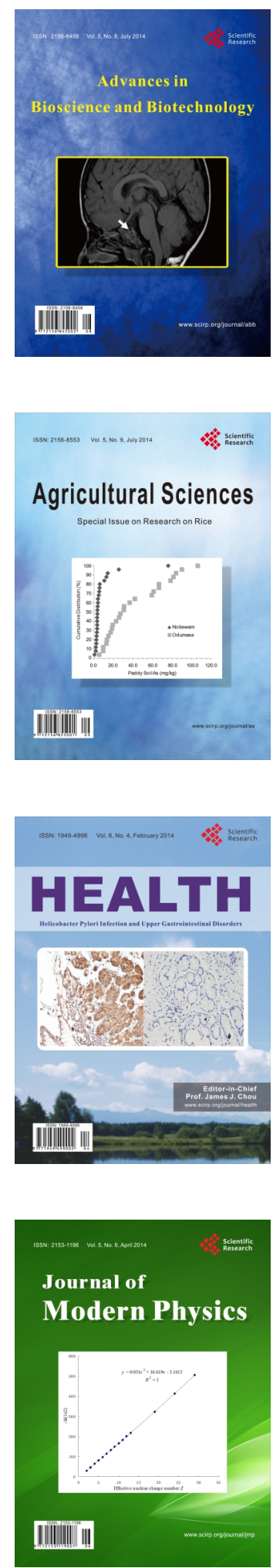
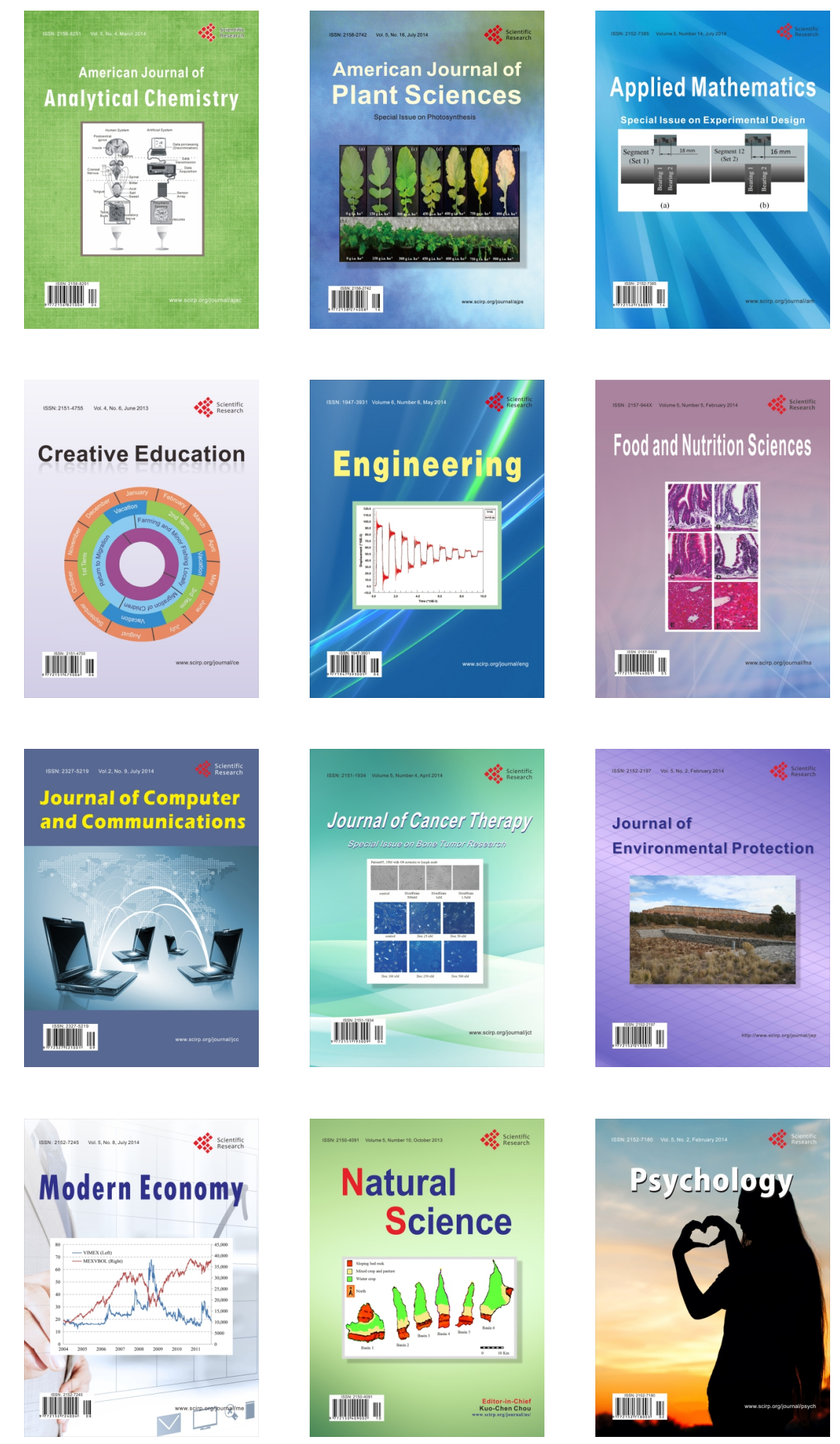